\title{
MiR-124 Inhibits Growth and Enhances Radiation-Induced Apoptosis in Non-Small Cell Lung Cancer by Inhibiting STAT3
}

\author{
Mengjie Wanga,b Bi Menga,b Yangchen Liu ${ }^{\mathrm{a}} \quad$ Jingwen Yu ${ }^{\mathrm{a}, \mathrm{c}} \quad$ Qiaoyun Chen ${ }^{\mathrm{a}}$ \\ Yanyan Liue \\ aBengbu Medical School, Bengbu, Anhui, 'bepartment of Radiotherapy, The Taixing People's \\ Hospital, Taixing, Jiangsu, 'Department of Gynecology, The Taixing People's Hospital, Taixing, Jiangsu, \\ dDepartment of Central Laboratory, The Affiliated People's Hospital, Jiangsu University, Zhenjiang, \\ Jiangsu, eDepartment of Radiotherapy, The Lianshui County People's Hospital, Lianshui, Jiangsu, \\ People's Republic of China
}

\section{Key Words}

Non-small-cell lung carcinoma $•$ MiR-124 • Radiosensitivity

\begin{abstract}
Background/Aims: A growing body of evidence indicates that the abnormal expression of microRNAs (miRNAs) play an important role in sensitizing the cellular response to ionizing radiation (IR). The aim of this study was to investigate whether the expression of miR-124 correlated with radiosensitivity in the context of non-small-cell lung carcinoma (NSCLC). Methods: Quantitative reverse transcription polymerase chain reaction (RT-PCR) was used to quantify miR-124 expression in NSCLC tissues and cell lines. The role of miR-124 in NSCLC proliferation and radiosensitivity was analyzed using CCK-8 and flow cytometry apoptosis assays. Luciferase activity assays, RT-PCR, and Western blot assays were performed to confirm the target gene of miR-124. Results: In this study, we found that miR-124 was downregulated both in clinical NSCLC samples and in cell lines. miR-124 inhibited the proliferation of NSCLC cells and enhanced the apoptosis of NSCLC cells exposed to ionizing radiation. We identified signal transducer and activator of transcription 3 (STAT3) as a direct target of miR-124 by using target prediction algorithms and luciferase assays. Overexpression of STAT3 in A549 cell lines restored the enhanced radiosensitivity induced by miR-124. Conclusion: Taking these observations into consideration, we illustrated that miR-124 is a potential target for enhancing the radiosensitivity of NSCLC cells by targeting STAT3.
\end{abstract}

M. Wang and B. Meng contributed equally to this work.

Yangchen Liu 


\section{Introduction}

Among malignant tumors in China, lung cancer, a common type of cancer, is the leading cause of death [1]. Non-small cell lung cancer (NSCLC), the most common type of lung cancer, accounts for approximately $80 \%$ of lung cancer cases [2]. Approximately two-thirds of NSCLC patients are diagnosed after the disease is already in advanced stages [2]. Radiation therapy is a powerful tool for treating locally advanced NSCLC [3]. However, radiation resistance is an obstacle to the successful treatment of NSCLC [4]. The key mechanisms that govern tumor radiation resistance remain unclear.

MicroRNAs (miRNAs) are a class of small ( $\sim 22$ nucleotides) non-coding RNA molecules that regulate gene expression by either targeting mRNA for degradation or by inhibiting mRNA translation [5]. Studies have demonstrated that miRNAs play important roles in biological processes, such as proliferation, differentiation and apoptosis. Some miRNAs have been confirmed to modulate the function of known oncogenes and tumor suppressor genes [6]. These miRNAs may be useful for predicting and modifying the effects of anticancer treatments (including chemotherapy, radiotherapy, and immunotherapy) [7, 8]. Moreover, a growing body of evidence suggests that some miRNAs are associated with radiotherapy resistance, particularly in lung cancer $[9,10]$.

miR-124 is a highly conserved miRNA that has been reported to be downregulated in many human malignant tumors, including gastric cancer, breast cancer, hepatocellular carcinoma and glioblastoma [11-15]. Furthermore, Deng et al. found that miR-124 can radiosensitize glioblastoma multiforme cells through the miR-124/CDK4 axis [16]. However, the function of miR-124 in tumor radioresistance remains poorly understood. In the present study, we explore the role of miR-124 in radiotherapy sensitivity in NSCLC and the potential molecular mechanism.

\section{Materials and Methods}

\section{Patient and tissue samples}

The study was approved by the Research Ethics Committee of Taixing People's Hospital. Paired NSCLC and para-carcinoma tissues were taken from 12 patients who underwent radical resections for primary tumors between 2015 and 2016 at Taixing People's Hospital. All participants signed the informed consent. Tumor tissues and adjacent normal tissues were obtained immediately after the resection. Fresh tissue was snap- frozen in liquid nitrogen and subsequently transferred to $-80^{\circ} \mathrm{C}$ for storage until further processing.

\section{Cell lines and culture conditions}

Three NSCLC adenocarcinomas cell lines (A549, NCI-H1299 and NCI-H1650) and a normal human bronchial epithelial cell line (BEAS-2B) were purchased from the Cell Bank of the Chinese Academy of Sciences (Shanghai, China). NSCLC cells and BEAS-2B cells were maintained in RPMI 1640 medium or DMEM (Gibco, Grand Island, NY, USA) supplemented with 10\% fetal bovine serum (FBS; Gibco), penicillin $(100 \mathrm{U} / \mathrm{ml})$ and streptomycin $(100 \mu \mathrm{g} / \mathrm{ml})$ (Beyotime Biotech, Haimen, China) in humidified air at $37^{\circ} \mathrm{C}$ with $5 \% \mathrm{CO}_{2}$.

\section{Cell transfection}

The miR-124 mimics and the negative control mimics (NCs) were purchased from GenePharma (Shanghai, China) and transfected into NSCLC cells at a final concentration of $30 \mathrm{nmol} / \mathrm{L}$. The transfection of NSCLC cells was performed with Lipofectamine ${ }^{\circledR} 2000$ (Life Technologies, NY, USA) according to the manufacturer's protocol. For each treatment group, the experiments were performed in triplicate. Transfection with STAT3-specific siRNA (siSTAT3) was performed as described previously [15].

RNA isolation and quantitative real-time PCR

Total RNA was extracted using TRIzol Reagent (Invitrogen, Carlsbad, CA) from the NSCLC cell lines and the tumor specimens previously stored at $-80^{\circ} \mathrm{C}$. First-strand cDNA was synthesized using a reverse 


\section{Cellular Physiology Cell Physiol Biochem 2017;44:2017-2028 \begin{tabular}{l|l|l} 
and Biochemistry & DOI: 10.1159/000485907 & $\begin{array}{l}\text { (c) } 2017 \text { The Author(s). Published by S. Karger AG, Basel } \\
\text { www.karger.com/cpb }\end{array}$
\end{tabular}}

Wang et al.: miR-124 and Radiation in NSCLC

transcription kit (Tiangen, Beijing, China). Quantitative RT-PCR assays were performed to detect the expression levels of mature miR-124 using an ABI TaqMan ${ }^{\circledR}$ MicroRNA Assay Kit (Applied Biosystems, Foster City, USA) and a Bio-Rad CFX-96 Real-Time PCR system. STAT3 mRNA levels were detected as previously described [17].

\section{Radiosensitivity assay}

A549 cells were seeded at $1 \times 10^{4}$ cells/well into a 96-well plate and transfected with either miR-124 mimics (30 nM) or negative control miRNA (30 nM). After a 24-h incubation, A549 cells were treated with various doses $(0,4$, or $8 \mathrm{~Gy})$ of radiation (IR). After exposure to the radiation for $72 \mathrm{~h}$, the radiosensitivity was measured using a Cell Counting Kit-8 (CCK-8) assay.

\section{Cell Counting Kit-8 (CCK-8) assay}

After treatment, A549 cells were seeded into a 96-well plate at a density of $1 \times 10^{4}$ cells/well and incubated for 96 hours. In vitro cell proliferation was measured using the Cell Counting Kit-8 (CCK-8) (Beyotime Biotech, Haimen, China) according to the manufacturer's instructions. The absorbance of each well at $450 \mathrm{~nm}$ (630 nm reference) was determined with a Multiskan FC microplate absorbance reader (Thermo Fisher, Grand Island, NY, USA). Each experiment was repeated in triplicate.

\section{Colony formation assay}

After exposure to various treatments, 200 cells were trypsinized, washed, seeded into 6-well plates and routinely cultured. Cells were grown for 14 days, fixed with ethanol, and stained with crystal violet to detect colonies. The number of colonies containing at least 50 cells was calculated.

\section{Cell cycle analysis by flow cytometry}

After a 48-h transfection period, A549 cells were trypsinized, washed with PBS and fixed in $75 \%$ ethanol at $4^{\circ} \mathrm{C}$ overnight. After a 24-h fixation period, the cells were washed with PBS and treated with propidium iodide (PI) stain (Beyotime Biotech) for $30 \mathrm{~min}$. Cell cycle analysis was conducted with a BD FACSCanto $^{\text {TM }}$ II flow cytometry system with a ModFit LT software package.

\section{Apoptosis assay}

Apoptosis was evaluated using the Annexin V-FITC Apoptosis Detection Kit (Beyotime Biotech, Haimen, China) according to the manufacturer's instructions. Cells $\left(1 \times 10^{5}\right)$ were transfected with miR-124 mimics or NCs for $48 \mathrm{~h}$ and stained with Annexin V-FITC. Cells were resuspended in binding buffer $(190 \mu \mathrm{L})$, followed by the addition of $10 \mu \mathrm{L}$ of PI $(20 \mu \mathrm{g} / \mathrm{mL})$, and incubated for at least $15 \mathrm{~min}$ at room temperature in the dark. Stained cells were analyzed with a BD FACSCanto ${ }^{\mathrm{TM}}$ II flow cytometry system. Early apoptosis was measured as the percentage of Annexin V-positive/PI-negative cells.

\section{Hoechst 33258 stain}

Following the experimental treatment, NSCLC cells were treated with Hoechst 33528 (5 mg/ml; Beyotime Biotech) for 10 min in the dark and then were washed thoroughly three times with PBS. Nuclear staining was detected under an Olympus IX73 inverted fluorescence microscope (Olympus Co. Ltd., Tokyo, Japan).

\section{Luciferase report assay}

The 3 '-UTR sequence of STAT3 from human genomic DNA containing the predicted miR-124 binding site was amplified by PCR. The 3'-UTR segment of STAT3 with the mutated miR-124 target site was generated with a QuikChange Site-Directed Mutagenesis Kit (Stratagene, La Jolla, CA, USA). A total of $1 \times 10^{4}$ cells were seeded per well in $150 \mu \mathrm{l}$ of RPMI 1640 medium. A total of $100 \mathrm{ng}$ of wild-type (wild) or mutant (mut) STAT3 3'-UTR reporter plasmids were co-transfected with Lipofectamine 2000 transfection reagent into A549 cells with $30 \mathrm{nM}$ miR-124 or NC according to the manufacturer's protocol. After $48 \mathrm{~h}$, luciferase activity was detected with the Dual-Luciferase Reporter Assay Kit (Promega Corp., Madison, WI, USA). 


\section{Cellular Physiology Cell Physiol Biochem 2017;44:2017-2028 \begin{tabular}{ll|l} 
and Biochemistry Published online: December 11, 2017 & $\begin{array}{l}\text { C) } 2017 \text { The Author(s). Published by S. Karger AG, Basel } \\
\text { www.karger.com/cpb }\end{array}$ \\
\hline
\end{tabular}

Western blot analysis

Proteins were separated by SDS-polyacrylamide gel electrophoresis and transferred to polyvinylidene difluoride (PVDF) transfer membranes (Millipore, Bedford, MA, USA). The membranes were blocked with $5 \%$ non-fat milk and incubated with the primary antibodies (rabbit anti-STAT3 monoclonal antibody or mouse anti-GAPDH monoclonal antibody; Abcam, Cambridge, MA, USA). Finally, the blots were incubated with HRP-conjugated goat anti-mouse or anti-rabbit antibody for $1.5 \mathrm{~h}$ at room temperature, and the blots were detected with enhanced chemiluminescence reagents (Beyotime, Haimen, China).

\section{Statistical analysis}

Data are presented as the means \pm standard deviations (S.D.s) of three independent experiments. The Statistical Package for the Social Sciences for Windows Version 12.0 was used to conduct all relative analyses with either Student's t-test or two-way ANOVA. $P<0.05$ was considered statistically significant.

\section{Results}

MiR-124 expression is downregulated in NSCLC cell lines and tissues

Real-time PCR assays revealed that miR-124 expression was markedly decreased in all three NSCLC cell lines, including A549, NCI-H1299 and NCI-H1650 cells, compared with the expression in the normal human bronchial epithelial BEAS$2 \mathrm{~B}$ cell line (Fig. 1A). Moreover, comparative analysis revealed that miR-124 expression was significantly downregulated in 12 pairs of NSCLC cancerous tissues compared with that in adjacent noncancerous tissues (Fig. $1 \mathrm{~B}, 1 \mathrm{C})$. Collectively, these results suggested that miR-124 was downregulated in NSCLC.

\section{Ectopic expression of miR-124 inhibited} the proliferation of NSCLC cells

To investigate the effect of miR124 on cell proliferation, we transfected the NSCLC A549 cell line with miR-124 mimics. The increased expression of miR124 after transfection was confirmed by quantitative real-time PCR (Fig. 2A). CCK-8 and colony formation assays showed that ectopic expression of miR-124 markedly inhibited the proliferation and growth
A

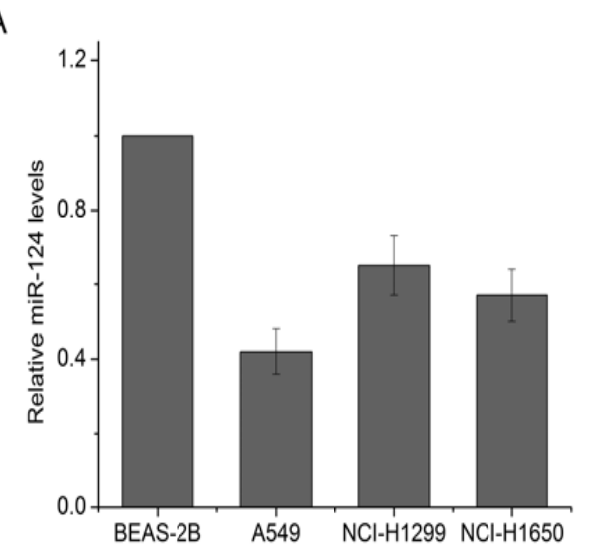

B

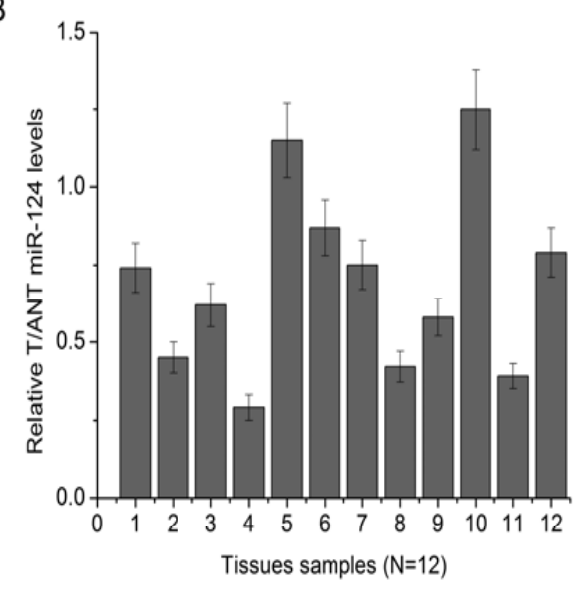

C

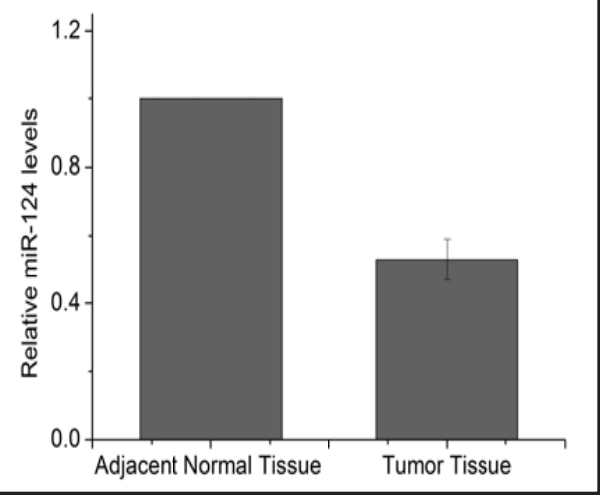

Fig. 1. Identification of the expression of miR-124 in human NSCLC tissues and cell lines. A. The expression level of miR-124 was detected in the normal human bronchial epithelial BEAS-2B cell line and in NSCLC cell lines. B, C. The expression levels of miR-124 in 12 pairs of NSCLC tissues and matched adjacent normal tissues were detected by real-time quantitative RT-PCR. T: tumor tissue; ANT: adjacent normal tissue. ${ }^{*} \mathrm{P}<0.05$. 
A

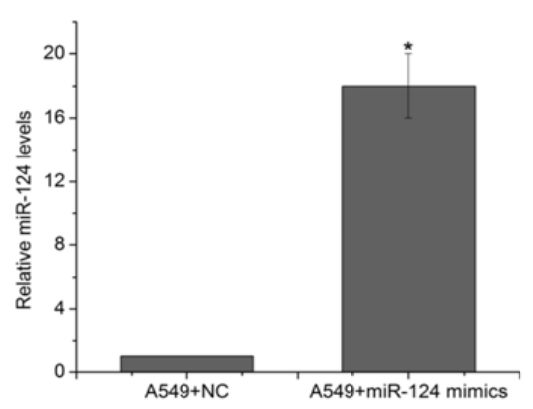

C

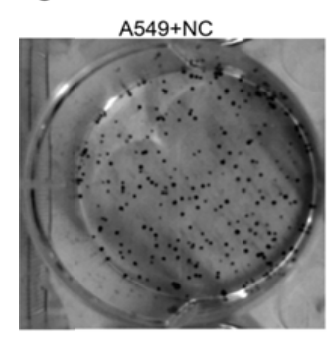

$E$
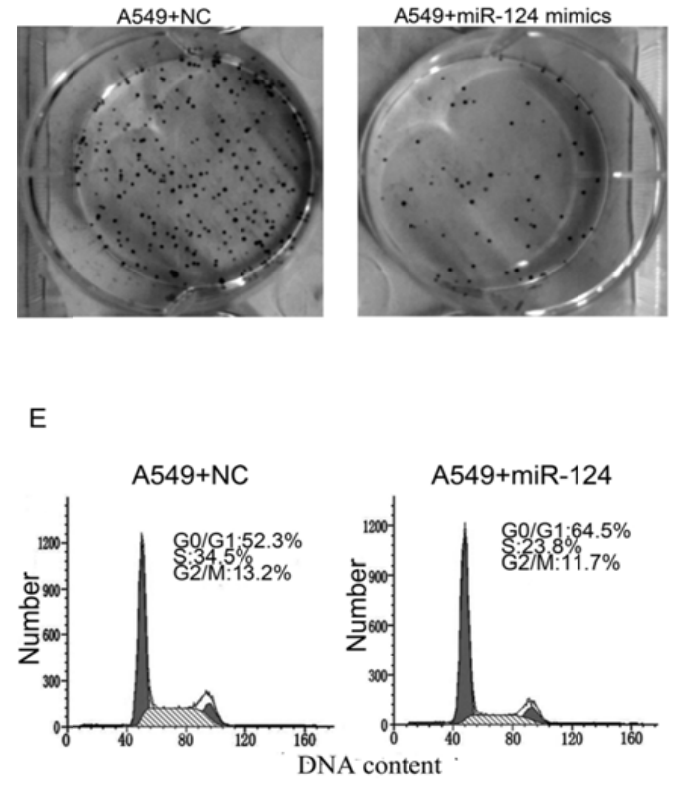

B

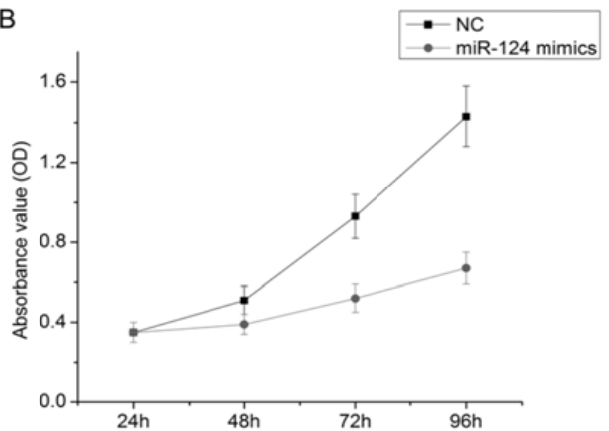

D

D

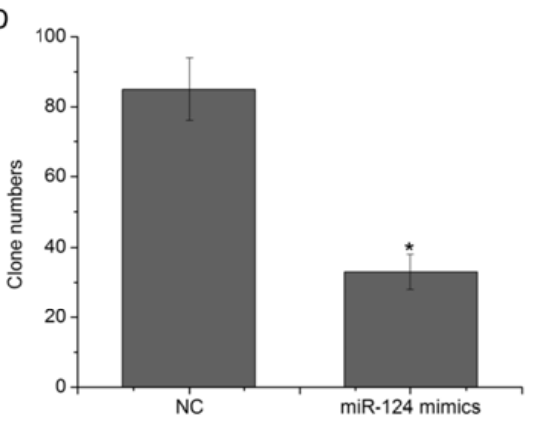

$\mathrm{F}$
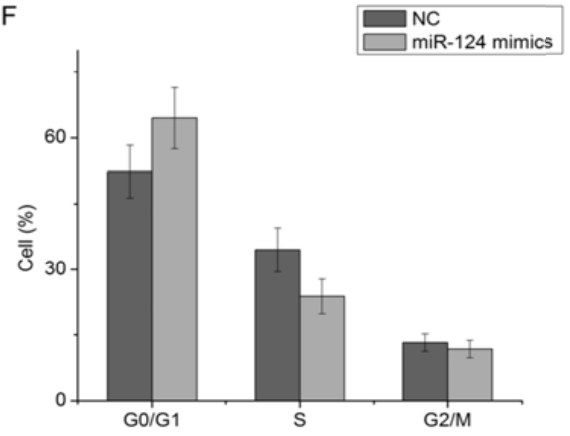

Fig. 2. miR-124 suppresses NSCLC cell growth and induces cell cycle arrest. A. miR-124 expression levels were examined to validate the effect of transfection on A549 cells. B. CCK-8 assays were performed every $24 \mathrm{~h}$ until $96 \mathrm{~h}$ after transfection, and the proliferation curves of A549 cells were plotted. C, D. Ectopic miR124 expression significantly inhibited A549 cell proliferation, as assessed by colony formation assay. E, F. PI staining and flow cytometry were used to analyze the cell cycle distribution of A549 cells. ${ }^{*} \mathrm{P}<0.05$.

of A549 cells compared with these parameters of the mimic control cells (Fig. 2B, 2C and 2D). The inhibition of proliferation may be partially due to disruptions in cell growth regulation, such as cell cycle arrest. Thus, we next explored if the decreased cell proliferation was the result of cell cycle arrest. At $48 \mathrm{~h}$ post-transfection, cell cycle analysis indicated that ectopic expression of miR-124 induced G0/G1 arrest in A549 cells (Fig. 2E and 2F).

Ectopic expression of miR-124 enhanced apoptosis in A549 cells induced by ionizing radiation

We next explored the role of miR-124 in the apoptosis of A549 cells induced by ionizing radiation (IR). MiR-124 mimics or NCs were transfected into A549 cells and exposed to IR. The results of the CCK- 8 assay indicated that miR-124 enhanced the radiosensitivity of A549 cells (Fig. 3A). As shown in Fig. 3B and 3C, the percentage of apoptotic cells in the miR-124 mimics-transfected group was significantly higher than that in the NCs-transfected group 


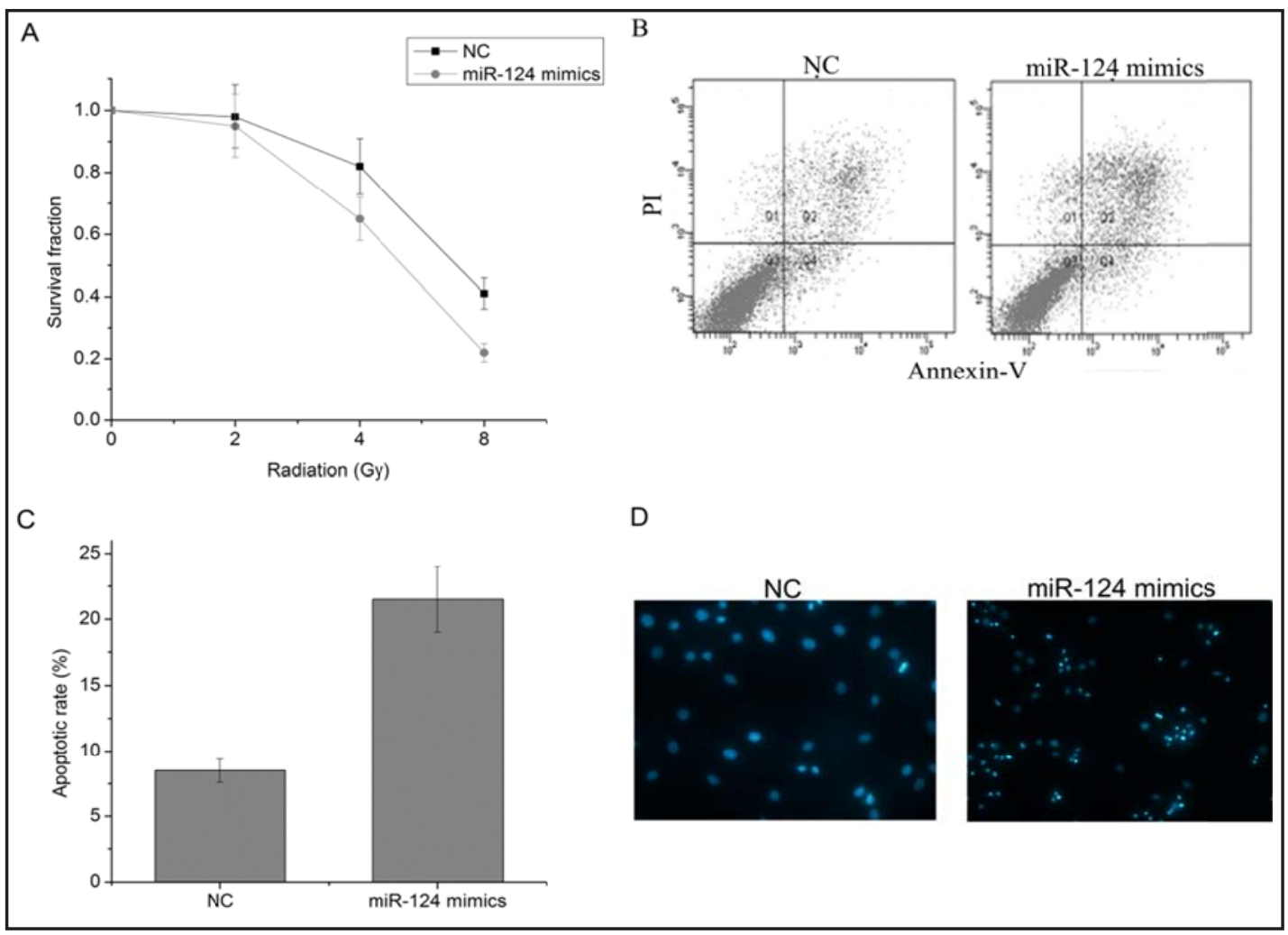

Fig. 3. MiR-124 enhanced the radiosensitivity of A549 cells. A. The radiosensitivity of A549 cells was detected by a CCK-8 assay. B, C. The apoptosis of A549 cells was detected by Flow CytoMeter. D. The apoptosis of A549 cells was detected by Hoechst 33528 staining.

at the dose 4 Gy $(22.5 \pm 2.5 \%$ versus $8.9 \pm 0.9 \%, P<0.05)$. Similar results were obtained by staining with Hoechst 33528 (Fig. 3D). As shown in Fig. 4A and 4B, the decrease in STAT3 expression levels after transfection of the miR-124 mimics was confirmed by quantitative real-time PCR in NCI-H1299 cells. Similarly, miR-124 inhibited the proliferation and enhanced the radiosensitivity of NCI-H1299 cells (Fig. 4C and 4D). These results indicated that the overexpression of miR-124 may enhance the radiosensitivity of NSCLC cells and thus confirmed that miR-124 is involved in the regulation of the radiotherapy response of NSCLC.

\section{MiR-124 directly regulates STAT3 gene expression in NSCLC cells}

To investigate the target genes of miR-124, the potential targets of miR-124 were predicted using the online tool TargetScanHuman 6.2 (http://www.targetscan.org/). Our analysis revealed that STAT3 was a potential target of miR-124 (Fig. 5A). To determine if miR-124 directly binds to the STAT3 3'UTR, a luciferase reporter gene assay was performed. A549 cells were co-transfected with luciferase reporter gene plasmids and miR-124 mimics or NCs. The miR-124 mimics, rather than the NCs, significantly inhibited the luciferase activity of the reporter gene containing the wild-type STAT3 3'UTR but did not affect the luciferase activity of the reporter gene containing the mutated STAT3 $3^{\prime}$ UTR (Fig. 5B). RT-PCR and Western blot assays confirmed that the overexpression of miR-124 decreased STAT3 mRNA and protein expression levels (Fig. 5C, 5D, and 5E). These results suggest that STAT3 is a direct target of miR-124.

\section{Expression of STAT3 restored the suppressive function of $\mathrm{miR}-124$}

We ectopically expressed recombinant STAT3 lacking the 3'-UTR sequence (pcDNA3.1STAT3) in A549 cells. A549 cells transfected with the miR-124 mimics showed significantly 


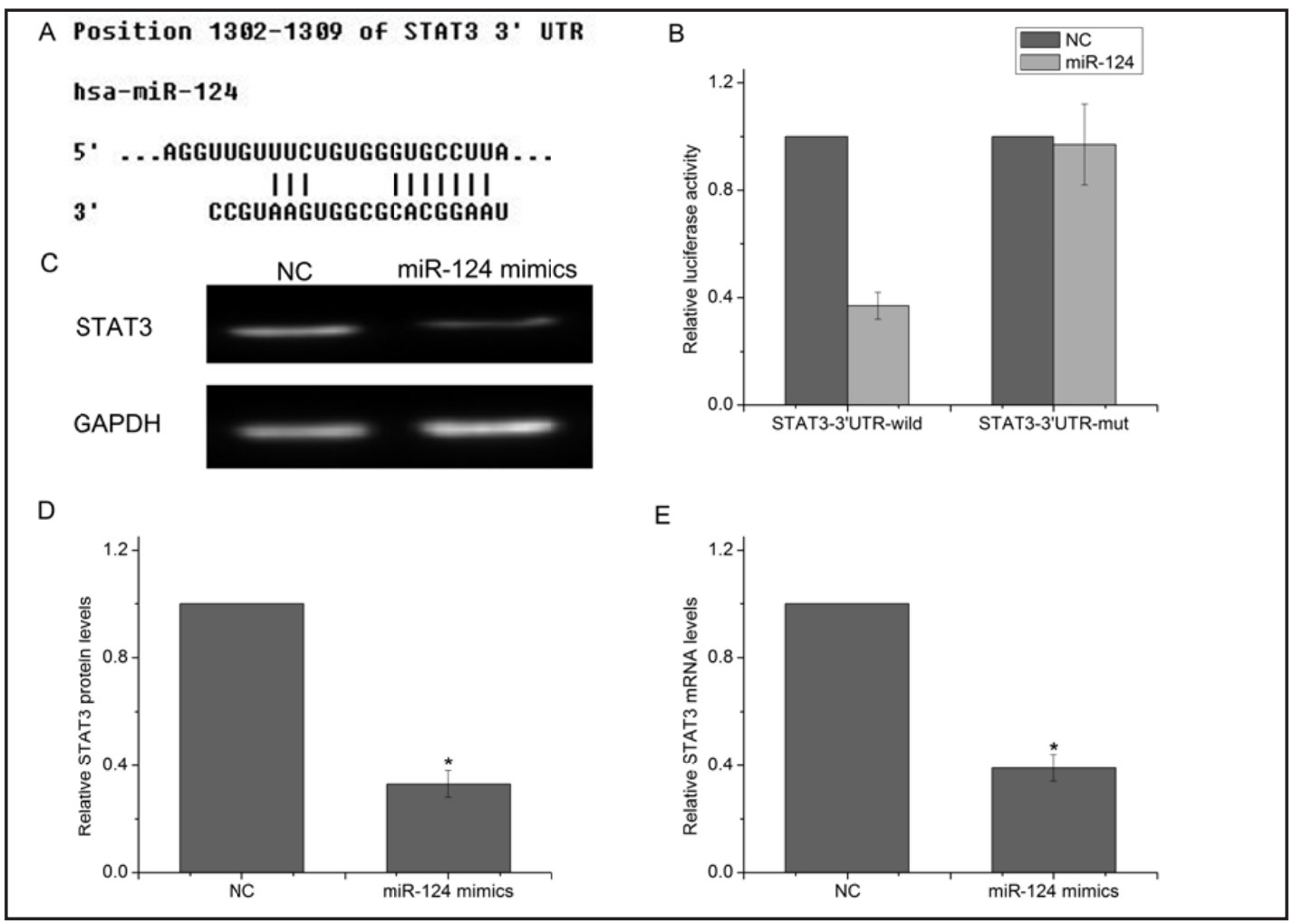

Fig. 4. miR-124 inhibited the proliferation and enhanced the radiosensitivity of NCI-H1299 cells. A, B. STAT3 protein expression levels were measured by Western blot assays after transfection with NCs or miR124 mimics. C. The proliferation of NCI-H1299 cells transfected with NCs or miR-124 mimics was detected by a CCK-8 assay. D. The radiosensitivity of NCI-H1299 cells transfected with NCs or miR-124 mimics was detected by a CCK-8 assay. ${ }^{*} \mathrm{P}<0.05$.

decreased levels of proliferation (Fig. 6A). The results of the CCK-8 assay indicated that the expression of STAT3 decreased the radiosensitivity of A549 cells (Fig. 6B). After exposing cells to ionizing radiation, there were significant differences between the apoptosis of cells transfected with miR-124 alone and those of cells co-transfected with both pcDNA3.1-STAT3 and miR-124 (Fig. 6C, 6D, 6E). The results showed that the expression of STAT3 restored the suppressive function of miR-124 in A549 cells.

miR-124 enhances the radiosensitivity of NSCLC cells in vivo

To investigate the role of miR-124 in radiosensitivity in a mouse xenograft model of NSCLC, A549 cells were injected subcutaneously into nude mice. The subcutaneous tumor was treated with a single dose of 8 Gy X-rays 10 days after the injection of either the miR124 mimics or negative control. As shown in Fig. 7A and 7B, we observed that the volumes of xenografts derived from A549 cells treated with miR-124 mimics were smaller than those of the NC group. In addition, we found that miR-124 expression levels were significantly increased in xenografts from miR-124 mimics-transfected cells compared to those in the NC group (Fig. 7C). STAT3 expression was also examined by Western blotting assays, and the results suggested that the STAT3 protein expression level was lower in xenograft tissues derived from cells with miR-124 mimics than in the NC group tissues (Fig. 7D, 7E). Taken together, these data indicate that miR-124 inhibition enhances the radiosensitivity of NSCLC cells in vivo by downregulating STAT3 expression. 


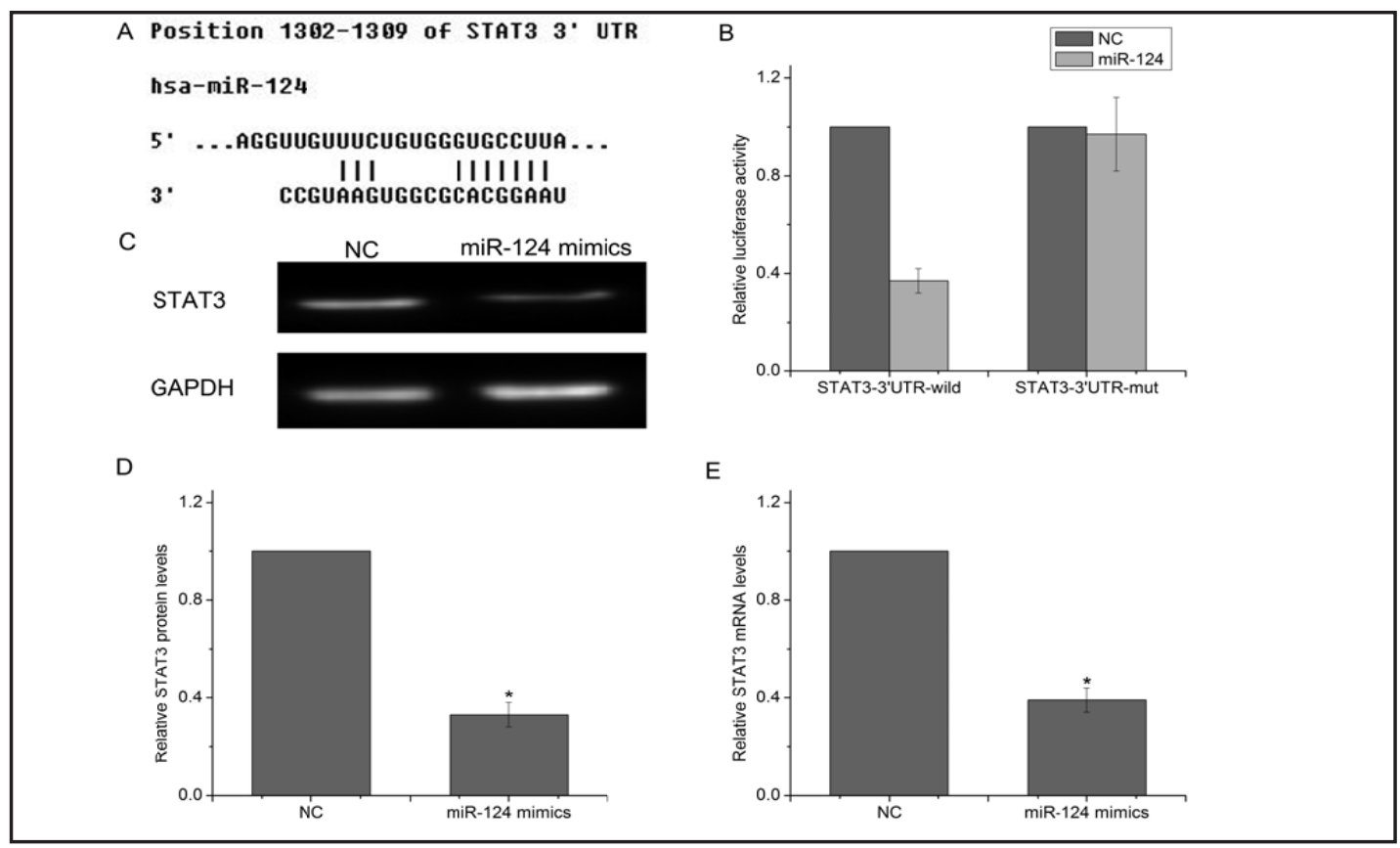

Fig. 5. STAT3 is a direct target of miR-124 in NSCLC cells. A. Seed sequences of miR-124 in the 3'-UTR of STAT3. B. Luciferase reporter assay data showed that co-transfecting A549 cells with miR-124 and WT STAT3 3'-UTR produced a significant decrease in luciferase activity, whereas co-transfection with the MUT STAT3 3'-UTR and miR-124 mimics demonstrated no difference compared with the control group. C, D. Western blot analysis was performed to examine the protein expression level of STAT3 in A549 cells transfected with miR-124 mimics or NCs. E: Reverse transcription-quantitative polymerase chain reactions were performed to examine STAT3 mRNA expression levels in A549 cells transfected with miR-124 mimics or NCs. ${ }^{*} \mathrm{P}<0.05$.

Fig. 6. Expression of STAT3 restored the suppressive function of miR-124. A. The proliferation of A549 cells was detected by CCK-8 assay. B. The radiosensitivity of A549 cells was detected by CCK-8 assay. C, D. The apoptosis of A549 cells was detected by FCM. E. The apoptosis of A549 cells was detected by Hoechst 33258 staining.
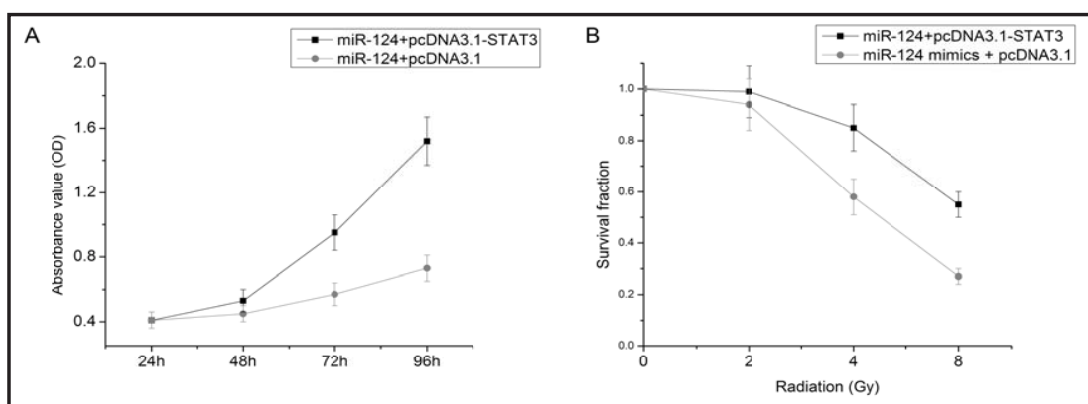

C

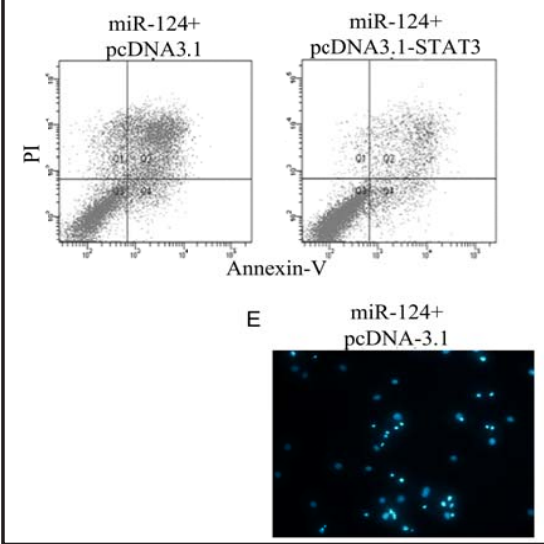

D

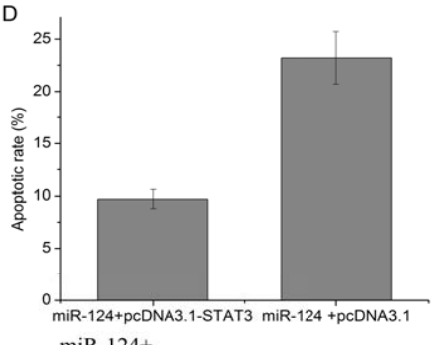

miR-124+

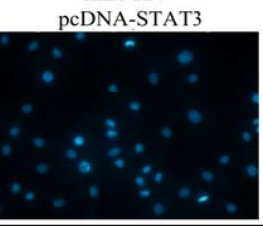




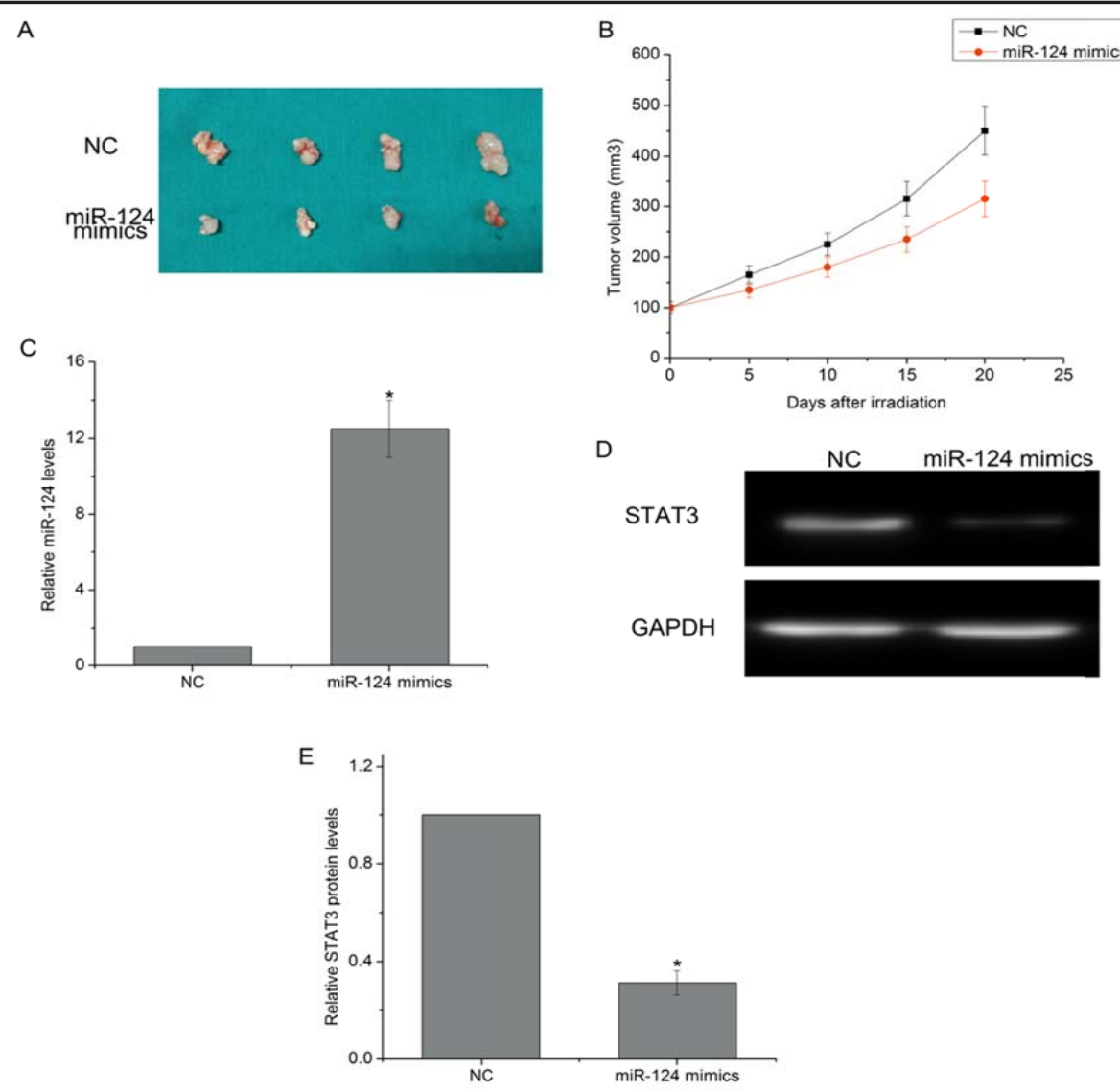

Fig. 7. miR-124 enhances the radiosensitivity of NSCLC cells in vivo. A. Image of xenografts in different groups 20 days after irradiation. B. Tumor growth curves of the different groups. C. miR-124 expression levels in xenografts from the different groups. D, E. STAT3 protein expression levels in xenografts from the different groups. ${ }^{*} \mathrm{P}<0.05$.

\section{Discussion}

The role of miRNA in cancer radiotherapy responses remain largely unexplored, though an increasing amount of evidence suggests that miRNAs can play a critical role in cancer [18]. In the present study, our findings demonstrated that miR-124 is involved in the radioresistance of NSCLC via the modulation of STAT3 and that the ectopic expression of miR-124 sensitizes A549 cells to irradiation in vitro. This study provides new evidence about the radioresistance mechanisms of lung cancer cells and suggests that miR-124 may be a potential sensitizer for radiation therapy.

miR-124, which is frequently decreased in a variety of human tumors, including gastric cancer, colorectal cancer, hepatocellular carcinoma, medulloblastoma, and glioblastoma, is the most abundant miRNA in the brain $[19,20]$. Several studies have demonstrated that miR-124 acts as a tumor suppressor in many cancers [21]. Zhang et al. found that miR124 can induce cell cycle arrest and inhibit the growth of bladder cancer by targeting CDK4 directly [22]. In gastric cancer, Hu et al. found that miR-124 inhibits the growth and invasion of GC cells by targeting ROCK1 [23]. Lv Z et al. revealed that miR-124 inhibits the growth of glioblastomas by targeting son of sevenless homolog 1 (SOS1) [14]. Furthermore, some studies have explored the association between miR-124 and radiation sensitivity. Zhang et al. found that miR-124 radiosensitizes human colorectal cancer cells and acts as a therapeutic target for CRC patients [24]. Deng et al. found that restoring miR-124 expression conferred

\section{KARGER}


radiosensitivity on human glioma cells [16]. In this study, we found that miR-124 expression is downregulated in NSCLC cell lines and tissues. Ectopic expression of miR-124 inhibited the proliferation of NSCLC cells and enhanced apoptosis in NSCLC cells induced by ionizing radiation. Our findings indicate that miR-124 acts as a tumor suppressor in NSCLC.

In this study, by using an online tool TargetScan Release 6.2 (http://www.targetscan. org/), we predicted that STAT3 may be a direct target of miR-124. Our hypothesis was also confirmed by luciferase reporter assays, Western blotting and RT-PCR. STAT3 has been extensively demonstrated to play a critical role in the tumorigenesis of various human malignancies [25]. For example, increased activation of STAT3 is a characteristic of various tumors and tumor cell lines [26,27]. Key gene expression changes modulated by the aberrant activation of STAT3 may promote cancer cell proliferation and survival and inhibit apoptosis $[28,29]$. In addition, Xie et al. reported that STAT3 may also play a role in cancer cell invasion and metastasis [30]. An increasing amount of evidence indicates that STAT3 activation is associated with radiotherapy sensitivity. Yang et al. found that celecoxib suppresses the phosphorylation of STAT3 protein expression and can enhance the radiosensitivity of medulloblastoma-derived cancer stem-like cells [31]. Zhang et al. reported that the STAT3 inhibitor NSC74859 radiosensitizes esophageal cancer cells via the downregulation of HIF-1 $\alpha$ [32]. In this study, we found that the overexpression of miR-124 enhanced the radiosensitivity of NSCLC cells. Our study and previous studies demonstrate that STAT3 is a direct target gene of miR-124. Furthermore, we found that the expression of STAT3 restored the suppressive function of miR-124. These results indicated that the miR-124/STAT3 axis is associated with the radiosensitivity of NSCLC cells.

\section{Conclusion}

In summary, our findings in the present study demonstrated that the miR-124/STAT3 axis plays an important role in the modulation of radiation sensitivity in NSCLC cells. Thus, miR-124 and STAT3 are potential radiosensitivity associated targets for the treatment of NSCLC. Further investigation through large clinical research studies is required to determine the clinical significance of both miR-124 and STAT3.

\section{Disclosure Statement}

The author(s) declare no potential conflicts of interest with respect to the research, authorship, and/or publication of this article.

\section{Acknowledgements}

The author(s) disclose receipt of the following financial support for this research, authorship, and/or publication of this article: this study was financially supported by the Taixing People's Hospital Fund Research Project (No: try1619) and the Bengbu Medical School graduate student scientific research innovation plan project (No. Byycx1624).

\section{References}

1 Siegel RL, Miller KD and Jemal A: Cancer statistics, 2016. CA Cancer J Clin 2016;66:7-30.

-2 Yin J, Wang M, Jin C and Qi Q: miR-101 sensitizes A549 NSCLC cell line to CDDP by activating caspase 3-dependent apoptosis. Oncol Lett 2014;7:461-465.

-3 McCloskey P, Balduyck B, Van Schil PE, Faivre-Finn C and O'Brien M: Radical treatment of non-small cell lung cancer during the last 5 years. Eur J Cancer 2013;49:1555-1564. 


\section{Cellular Physiology Cell Physiol Biochem 2017;44:2017-2028 \begin{tabular}{l|l|l} 
and Biochemistry Published onlIne: December 11, 2017 & $\begin{array}{l}\text { (c) } 2017 \text { The Author(s). Published by S. Karger AG, Basel } \\
\text { www.karger.com/cpb }\end{array}$ \\
\hline
\end{tabular}}

Wang et al.: miR-124 and Radiation in NSCLC

4 Wu Y, Zheng Y, Shen Z, Ge W, Xie Y and Li C: Endostar combined with radiotherapy increases radiation sensitivity by decreasing the expression of TGF-beta1, HIF-1alpha and bFGF. Exp Ther Med 2014;7:911916.

5 Fish JE, Santoro MM, Morton SU, Yu S, Yeh RF, Wythe JD, Ivey KN, Bruneau BG, Stainier DY and Srivastava D: miR-126 regulates angiogenic signaling and vascular integrity. Dev Cell 2008;15:272-284.

6 Shenouda SK and Alahari SK: MicroRNA function in cancer: oncogene or a tumor suppressor? Cancer Metastasis Rev 2009;28:369-378.

-7 Oh JS, Kim JJ, Byun JY and Kim IA: Lin28-let7 modulates radiosensitivity of human cancer cells with activation of K-Ras. Int J Radiat Oncol Biol Phys 2010;76:5-8.

-8 Wang P, Chen L, Zhang J, Chen H, Fan J, Wang K, Luo J, Chen Z, Meng Z and Liu L: Methylation-mediated silencing of the miR-124 genes facilitates pancreatic cancer progression and metastasis by targeting Rac1. Oncogene 2014;33:514-524.

-9 Salim H, Akbar NS, Zong D, Vaculova AH, Lewensohn R, Moshfegh A, Viktorsson K and Zhivotovsky B: miRNA-214 modulates radiotherapy response of non-small cell lung cancer cells through regulation of p38MAPK, apoptosis and senescence. Br J Cancer 2012;107:1361-1373.

10 Yan D, Ng WL, Zhang X, Wang P, Zhang Z, Mo YY, Mao H, Hao C, Olson JJ, Curran WJ and Wang Y: Targeting DNA-PKcs and ATM with miR-101 sensitizes tumors to radiation. PLoS One 2010;5:e11397.

11 Xia J, Wu Z, Yu C, He W, Zheng H, He Y, Jian W, Chen L, Zhang L and Li W: miR-124 inhibits cell proliferation in gastric cancer through down-regulation of SPHK1 J Pathol 2012;227:470-480.

12 Han ZB, Yang Z, Chi Y, Zhang L, Wang Y, Ji Y, Wang J, Zhao H and Han ZC: MicroRNA-124 suppresses breast cancer cell growth and motility by targeting CD151. Cell Physiol Biochem 2013;31:823-832.

13 Zheng F, Liao YJ, Cai MY, Liu YH, Liu TH, Chen SP, Bian XW, Guan XY, Lin MC, Zeng YX, Kung HF and Xie D: The putative tumour suppressor microRNA-124 modulates hepatocellular carcinoma cell aggressiveness by repressing ROCK2 and EZH2 Gut 2012;61:278-289.

14 Lv Z and Yang L: MiR-124 inhibits the growth of glioblastoma through the downregulation of SOS1 Mol Med Rep 2013;8:345-349.

15 Zhou L, Xu Z, Ren X, Chen K and Xin S: MicroRNA-124 (MiR-124) Inhibits Cell Proliferation, Metastasis and Invasion in Colorectal Cancer by Downregulating Rho-Associated Protein Kinase 1(ROCK1). Cell Physiol Biochem 2016;38:1785-1795.

16 Deng X, Ma L, Wu M, Zhang G, Jin C, Guo Y and Liu R: miR-124 radiosensitizes human glioma cells by targeting CDK4. J Neurooncol 2013;114:263-274.

17 Zhao G, Zhang JG, Shi Y, Qin Q Liu Y, Wang B, Tian K, Deng SC, Li X, Zhu S, Gong Q, Niu Y and Wang CY: MiR-130b is a prognostic marker and inhibits cell proliferation and invasion in pancreatic cancer through targeting STAT3. PLoS One 2013;8:e73803.

18 Mei Z, He Y, Feng J, Shi J, Du Y, Qian L, Huang Q and Jie Z: MicroRNA-141 promotes the proliferation of nonsmall cell lung cancer cells by regulating expression of PHLPP1 and PHLPP2. FEBS Lett 2014;588:30553061.

19 Li KK, Pang JC, Ching AK, Wong CK, Kong X, Wang Y, Zhou L, Chen Z and Ng HK: miR-124 is frequently down-regulated in medulloblastoma and is a negative regulator of SLC16A1. Hum Pathol 2009;40:12341243.

20 Xie L, Zhang Z, Tan Z, He R, Zeng X, Xie Y, Li S, Tang G, Tang H and He X: MicroRNA-124 inhibits proliferation and induces apoptosis by directly repressing EZH2 in gastric cancer. Mol Cell Biochem 2014;392:153-159.

21 Ma T, Zhao Y, Wei K, Yao G, Pan C, Liu B, Xia Y, He Z, Qi X, Li Z, Wang J and Shao Y: MicroRNA-124 Functions as a Tumor Suppressor by Regulating CDH2 and Epithelial-Mesenchymal Transition in Non-Small Cell Lung Cancer. Cell Physiol Biochem 2016;38:1563-1574.

22 Zhang T, Wang J, Zhai X, Li H, Li C and Chang J: MiR-124 retards bladder cancer growth by directly targeting CDK4. Acta Biochim Biophys Sin (Shanghai) 2014;46:1072-1079.

23 Hu CB, Li QL, Hu JF, Zhang Q, Xie JP and Deng L: miR-124 inhibits growth and invasion of gastric cancer by targeting ROCK1. Asian Pac J Cancer Prev 2014;15:6543-6546.

24 Zhang Y, Zheng L, Huang J, Gao F, Lin X, He L, Li D, Li Z, Ding Y and Chen L: MiR-124 Radiosensitizes human colorectal cancer cells by targeting PRRX1. PLoS One 2014;9:e93917.

-25 Hu W, Jin P and Liu W: Periostin Contributes to Cisplatin Resistance in Human Non-Small Cell Lung Cancer A549 Cells via Activation of Stat3 and Akt and Upregulation of Survivin. Cell Physiol Biochem 2016;38:1199-1208. 


\section{Cellular Physiology Cell Physiol Biochem 2017;44:2017-2028 \begin{tabular}{l|l|l} 
DOI: 10.1159/000485907 & $\begin{array}{l}\text { O 2017 The Author(s). Published by S. Karger AG, Basel } \\
\text { www.karger.com/cpb }\end{array}$ \\
\hline
\end{tabular}}

Wang et al.: miR-124 and Radiation in NSCLC

-26 Yang J, Chatterjee-Kishore M, Staugaitis SM, Nguyen H, Schlessinger K, Levy DE and Stark GR: Novel roles of unphosphorylated STAT3 in oncogenesis and transcriptional regulation. Cancer Res 2005;65:939-947.

-27 de la Iglesia N, Konopka G, Puram SV, Chan JA, Bachoo RM, You MJ, Levy DE, Depinho RA and Bonni A: Identification of a PTEN-regulated STAT3 brain tumor suppressor pathway. Genes Dev 2008;22:449-462.

-28 Epling-Burnette PK, Liu JH, Catlett-Falcone R, Turkson J, Oshiro M, Kothapalli R, Li Y, Wang JM, Yang-Yen HF, Karras J, Jove R and Loughran TP, Jr.: Inhibition of STAT3 signaling leads to apoptosis of leukemic large granular lymphocytes and decreased Mcl-1 expression. J Clin Invest 2001;107:351-362.

29 Kim KW, Mutter RW, Cao C, Albert JM, Shinohara ET, Sekhar KR and Lu B: Inhibition of signal transducer and activator of transcription 3 activity results in down-regulation of Survivin following irradiation. Mol Cancer Ther 2006;5:2659-2665.

30 Xie TX, Wei D, Liu M, Gao AC, Ali-Osman F, Sawaya R and Huang S: Stat3 activation regulates the expression of matrix metalloproteinase-2 and tumor invasion and metastasis. Oncogene 2004;23:3550-3560.

-31 Yang MY, Lee HT, Chen CM, Shen CC and Ma HI: Celecoxib suppresses the phosphorylation of STAT3 protein and can enhance the radiosensitivity of medulloblastoma-derived cancer stem-like cells. Int J Mol Sci 2014;15:11013-11029.

-32 Zhang C, Yang X, Zhang Q, Guo Q, He J, Qin Q Zhu H, Liu J, Zhan L, Lu J, Liu Z, Xu L, Ma J, Dai S, Cheng H and Sun X: STAT3 inhibitor NSC74859 radiosensitizes esophageal cancer via the downregulation of HIF-1alpha. Tumour Biol 2014;35:9793-9799. 